\title{
Peter Király
}

\section{Die Schmidtbau(e)rs - Angaben zu Mitgliedern einer Musikerfamilie des späten 17. und frühen 18. Jahrhunderts ${ }^{1}$}

Die Musikgeschichtsschreibung kennt vier Schmidtbaur/Schmidtpaur (seltener Schmidtpauer usw.) genannte Musiker, die um die Wende des 17. zum 18. Jahrhundert aktiv waren: Franz und Ferdinand Schmidtbaur, die in Eisenstadt in Diensten des ungarischen Hochadeligen Paul Esterházy standen, sowie deren Bruder Johann Carl Schmidtbau(e)r und dessen Sohn Franz Anton Schmidtbauer ${ }^{2}$, die in der kaiserlich-königlichen Hofkapelle von Wien wirkten. Ihre Verwandtschaft wurde zwar angenommen, und in einer unveröffentlichten Maschinenschrift von János (Johann) Hárich sogar teils belegt ${ }^{3}$, eingehend wurden ihre Familienverhältnisse und Herkunft aber nie weiter untersucht. Dabei kursieren vor allem über den Esterházyschen Regens chori Franz Schmidtbaur, aber auch seinen Bruder Johann Carl falsche Behauptungen. Im Falle Franz Schmidtbaurs lässt sich

\footnotetext{
${ }^{1}$ Diese Studie ist Teil eines vom Ungarischen Forschungsfond OTKA unterstützten Esterházy-Forschungsprojektes (OTKA K 116154); eine etwas abweichende ungarische Fassung erschien unter Adalékok az Esterházy Pál udvari együttesét 1678-1701 között vezető Franz Schmidtbaur életrajzához, Zenetudományi dolgozatok, Budapest 2018, S. 126-141. Die benutzten Kirchenmatriken aus Wien, Obernzell, Kirchberg und Salzburg sind im Internet als Digitalisat erreichbar unter: data.matricula-online.eu/de/bestande/ (Stand: 9.08. 2018.); Für ihre vielfältige kollegiale Hilfe sei hier ausdrücklich bedankt bei István Fazekas (Budapest), Maria Knapp (Winkl), István Monok (Budapest), Josef Pratl (Eisenstadt), Herbert Seifert (Baden bei Wien), Georg Schurm (Hauzenberg), Noémi Viskolcz (Miskolc)

${ }^{2}$ In der vorliegenden Studie wird bevorzugt die Namensform „Schmidtbaur“ verwendet. Der Name wird in den Quellen dem örtlichen Dialekt entsprechend unterschiedlich festgehalten: in Obernzeller und Eisenstädter Dokumenten meistens mit „p“ als "Schmidtpaur“, in den Kirchberger Kirchenmatriken hingegen eher mit „b“ als "Schmidtbaur“. Man begegnet auch weiteren orthographischen Abweichungen wie Schmidbaur, Schmiedbauer, Schmidtbauer usw. Auch die Familie war diesbezüglich uneins. Am 21. Februar 1713 unterschrieb Franz Anton Schmidtbaur als „Schmidtbauer“, während sich seine Mutter und Schwester ohne „e“ als „Schmidtbaurin“ bezeichneten. Wien, Österreichisches Staatsarchiv, Haus- Hof und Staatsarchiv, Hofarchive, Akten des Obersthofmarschalamts, 661, Abhandlungen 1510 bis 1589 (1713-1714), Verlassenschaftsabhandlung Karl Schmidtbauer, kaiserlicher Musiker (1714. 04. 16).

3 János Hárich, Esterházy zenetörténet, [Esterházy Musikgeschichte] Maschinenschrift, 1946, Budapest, (Országos Széchényi Könyvtár, Kézirattár, Quart Hung. 2913) Heft. II. S. 46 und 88 .
} 
sogar feststellen, dass fast alles, was man früher zu wissen glaubte, nicht mit den historischen Tatsachen übereinstimmt.

Nach wiederholten Mitteilungen von Hárich soll Paul Esterházy den Musiker Franz Schmidtbaur am 1. Juli 1678 in seinen Diensten aufgenommen haben $^{4}$. Aus einem Vertrag vom 1. Januar 1705 - worauf später noch zurückzukommen sein wird -, vereinbart zwischen Paul Esterházy und Johann Carl Schmidtbaur, dem in Wien aktiven Bruder seines damals schon verstorbenen Hofmusikers, erfährt man jedoch, dass Franz Schmidtbaur Esterházy „bis $30 \mathrm{Jahr}$ lang treue dienst geleistet“ habe ${ }^{5}$. Zurückgerechnet von dem am 22. März 1701 erfolgten Tode Franz Schmidtbaurs, kommt man also auf ca. 1671 als möglichen Eintrittszeitpunkt des Musikers - wenn es tatsächlich so gewesen ist. Es bleibt nämlich unklar, ob diese Aussage „bis $30 \mathrm{Jahr}$ lang“ von dem in puncto Datum- und Zeitangaben notorisch ungenauen Paul Esterházy stammt ${ }^{6}$, oder eventuell von einem präziseren

\footnotetext{
${ }^{4}$ János Hárich, „Az Esterházy-zenekar első karmestere“, [Der erste Dirigent des Esterházy-Ensembles] Muzsika 1 (1929) nr. 3. S. 25.: „Ezért fogadta szolgálatába 1678. július elején ...“ [„Deshalb nahm er ihn am 1. Juli 1678 in seine Dienste“]; Ders. Esterházy zenetörténet, op. cit. Heft. II, S. 46: „Az egyházi zenélés tökéletesítése és fejlesztése lebegett Esterházy Pál előtt, midőn 1678. júlis 1-én Schmidtbauer Ferenc viola da gamba játékost szerződtette és őt bízta meg a kar vezetésével és felügyeletével“, [„Paul Esterházy schwebte die Perfektionierung der Kirchenmusik vor als er am 1. Juli 1678 den Viola da Gamba Spieler Franz Schmidtbauer unter Vertrag nahm und ihn mit der Chorleitung und Überwachung dessen beauftragte"] Ebda. Heft. III. S. 41.: „Schmidtbauer Ferenc: 1678-1701“.

${ }^{5}$ Hárich, Esterházy zenetörténet, o. cit. Heft II. S. 87-88. Als Quelle gibt Hárich an: „Pál nádor iratai, Protocollum XVII. 535“.

${ }^{6}$ Vgl. Berényi László, Esterházyak. Egy ezeréves család története, [Die Esterházys. Geschichte einer tausendjährigen Familie] Esterháza 2014, Bd. II. S. 419, wonach Paul Esterházy mit Zahlen und Daten seit seiner Kindheit auf „Kriegsfuß“ stand und sogar das Datum seiner Heirat mehrmals falsch angab. (,a számokkal, különösen a dátumokkal, már gyermek korától kezdve hadilábon állt. Így hát élete néhány olyan fontos eseményének, mint például saját esküvőjének dátumát többször is elhibázza.“); Bezeichnend ist, dass Esterházy von einer Schussverletzung seiner Schwester Anna Júlia, welche nachweislich noch vor seiner Geburt passierte, so erzählt, als ob er persönlich dabei gewesen wäre. Siehe Noémi Viskolcz, Esterházy Anna Júlia (1630-1669), Századok 149 (2015), nr. 4. S. 876.; Seinen in modernen Publikationen oft erwähnten Heiduckentanz vor der Kaiserin datierte Esterházy auch zwei Jahre zu früh auf 1647, obwohl er nur 1649 stattfinden konnte. Siehe Péter Király, Mikor járt hajdútáncot Esterházy Pál a császárné előtt? [Wann tanzte P. Esterházy den Hayduckentanz vor der Kaiserin?] (In Vorbereitung); Für eine Richtigstellung der Angaben in Esterházys Beschreibung seiner Reise mit seinem Schwager Ferenc III. Nádasdy nach Regensburg (Itinerarium in Germaniam), wo sie an der Kaiserkrönung teilnahmen, siehe: Péter Király, Itinerarium in Germaniam 1653 — Nádasdy Ferenc és Esterházy Pál regensburgi útja az újabb ismeretek tükrében,
} 
Eisenstädter Hofbeamten. Unabhängig von dieser Unsicherheit bleibt aber Tatsache, dass Franz Schmidtbaur vor dem 1. Juli 1678 schon zu den esterházyschen Musikern gehörte. Dies belegt nämlich eben der Vertrag von 1678, womit der vorher „cum Violdegamba“ dienende Schmidtbaur befördert und mit der Leitung des Musikensembles betraut wurde. Die in dieser Beförderungsurkunde verwendete Formel „conventum est cum ... nostro“ bezeugt eindeutig, dass Esterházy hier eine schon in seinen Diensten stehende Person zum Leiter seiner Hofmusik machte?

Diese Tätigkeit Schmidtbaurs wurde erst in späteren - im Verlauf dieser Studie noch zu erwähnenden - Dokumenten mit den Fachbegriffen „regens chori“" oder „capell maister" benannt. Man gewinnt den Eindruck, dass in Paul Esterházys Hofhaltung die Notwendigkeit eines institutionellen „offiziellen“ Leiters des Ensembles - trotz der nachweislich d = echt großen Anzahl von Hofmusikern ${ }^{8}$ - erst in den späteren Jahren allmählich erkannt, und offensichtlich sogar danach zeitweilig für als nicht unverzichtbar gehalten wurde9. Die Aufgaben von Schmidtbaur und dessen

[Itinerarium in Germaniam 1653 - die Reise von F. Nádasdy und P. Esterházy nach Regensburg im Spiegel neuerer Erkenntnisse] in: Esterházy Pál, a múkedvelő mecénás, hrsg. von Pál Ács, Budapest 2015. S. 417-434.

${ }^{7}$ Schmidtbaur wird nicht erwähnt in einer Auflistung von 1673, „Catalogus Auliocorum comitis Pauli Esteras: 1673“ (Magyar Nemzeti Levéltár, Országos Levéltár, Budapest, P 125. Esterházy Pál, Nr. 10674.) in der auch Musiker (je ein Geiger, Dudelsackspieler und Zimbalspieler, fünf Trompeter, ein Tympanist sowie sechs ungarische und polnische Pfeifer) aufgeführt sind. Dies ist eine Reiseliste von einigen wenigen Musikern, die mit Esterházy zeitweilig in Sempte in Oberungarn (heute Šintava, SK) waren. Eine ähnliche Reiseaufstellung von Musikern wird 1683 im Rahmen von Esterházys Militäraufgebot dokumentiert: je ein Geiger und Zimbalspieler sowie sechs ungarische und vier deutsche Trompeter, ein Tympanist, drei polnische Pfeifer und zwei ungarische Tárogató-Pfeifer. Siehe: Kálmán Thaly, Az 1683-iki táborozás történetéhez. A kétszázados évfordulat alkalmából hg. Eszterházy Pál nádor kiadatlan kéziratai s levelezései nyomán, [Das Lager von 1683. Anlässlich des zweihundertsten Jahrestages veröffentlicht anhand von P. Esterházys unpublizierten Handschriften und Korrespondenz] Budapest 1883, S. 34.

${ }^{8}$ Aus den gut 60 Jahren, in denen Paul Esterházy Familienoberhaupt war, kennt man gegenwärtig anhand von diversen Quellen etwa 140 Musiker in seinen Diensten. Siehe dazu: Hárich, Esterházy zenetörténet, op. cit. Heft II.-III. passim und die Auflistung der Musiker im Heft III. S. 38-45; Eine frühere Auflistung der Trompeter: Hárich, Az Esterházyak udvari és tábori trombitásai [Die Hof- und Feldtrompeter der Esterházy], Muzsika 1(1929) Nr. 6.7., (Juli-August) S. 59.; Ulrich Tank, Studien zur Esterházyschen Hofmusik, Regensburg 1981, S. 38-77, und Musikerlisten auf S. 96-126.; Pratl/Scheck 1, (EHB 4) S. 17-20; Pratl/ Forchtenstein, (EHB 7) S. 26-35; Pratl/Scheck 2, (EHB 10) S. 32-41.

${ }^{9}$ Nachdem Paul Esterházy 1704 die meisten seiner Hofmusiker, darunter auch den Kapellmeister Franz Rumpelnig, entlassen hat, taucht in den heute bekannten Dokumenten bis 1713/1714 kein Hinweis auf einen Leiter des Eisenstädter Ensemble auf. Es wurde zwar 
Vorgängers Paul Franz Klebovszky, der vom Frühjahr 1674 an den Musikern vorstand, wurden in ihren Verträgen noch in der Weise beschrieben, dass man ihre Tätigkeit und Funktion mit keinem Terminus bezeichnete. Trotzdem sind beide Urkunden wichtige Zeugnisse der Esterházy-Musikgeschichte.

Der Vertrag mit Klebovszky, ähnlich wie andere damalige Verträge mit Hofbediensteten in Ungarn („Convention“ genannt), verlangt an erster Stelle Treue. Darüber hinaus teilt er noch kurz mit, dass jedes Werk hervorragend auszuführen sei. Des Weiteren sollte Klebovszky im Chor auf den Takt aufpassen (wohl dass die Musiker während des Spiels „zusammenbleiben") und die Verteilung der Stimmen überwachen, d.h. darüber entscheiden, wer welche Stimme spielt oder singt $t^{10}$.

Die vier Jahre spätere Anweisung an Schmidtbaur ist schon wesentlich detaillierter: Er hat den Schlüssel des Chores und soll auf die dort befindlichen Instrumente aufpassen. Letztere dürfen nur für den Gottesdienst und Hofbedarf benutzt werden. Die anderen Musiker sind ihm unterstellt, der Gottesdienst solle fleißig begleitet werden und während dessen dürfe kein Skandal passieren. Er solle fleißig mit den anderen musizieren. Ohne Erlaubnis des Dienstherren (bzw. falls der verreist ist, vom Schlosspropst) dürfe Schmidtbaur nicht fehlen. Er solle auch fleißig komponieren. Falls man ihm Schüler zuweist, solle er diese fleißig unterrichten ${ }^{11}$.

von Harald Dreo angenommen, dass bis 1713 oder gar bis Sommer 1714, als Wenceslaus Zivilhoffer als Kapellmeister in Erscheinung tritt, Rumpelnig den Musikern vorstand, dies lässt sich aber dokumentarisch nicht belegen. Siehe Harald Dreo, Die fürstlich Esterházysche Musikkapelle von ihren Anfängen bis zum Jahre 1766, in: Beiträge zur Musikgeschichte des 18. Jhs. (Jahrbuch für österreichische Kulturgeschichte. Bd. I/2.) Eisenstadt 1971, S. 91; Dreos Annahme wird wiederholt von Tank, Studien, S. 57.

${ }^{10}$ Hárich, Esterházy zenetörténet, op. cit. Heft II. S. 82.: „Obligatur ipse ad fidelia servitia, quandocumque opus fuerit semper praestanda, habeatque curam in chor ad dandum tactum, et partes distribuendas"

${ }^{11}$ DerQuellentextaus demim Esterházy-Bestand des Ungarischen Staatsarchivs in Budapest nicht vorhandenen Conventionsbuch (d.h. Buch der Verträge mit Hofbediensteten) von 1675-1682 wurde in zwei geringfügig abweichender Lesarten von Hárich transcribiert. Siehe János Hárich, Az Esterházy-zenekar első karmestere. op. cit. S. 25. bzw. Hárich, Esterházy zenetörténet, op. cit. Heft II. S. 89-90.: „Anno 1678 die 1ma Julij conventum est cum Violdegamba nostro Francisco Smitpaur, habebit solutionem annualem in paratis f. 130, mensam ordinariam cum reliquis musicis corralibus qui ipsemet claves chori cum directione musicae habebit et reliqui dependentiam ab ipso ut officium Divinum diligentius exhibeatur, maiori cum fervore plerumque [Esterházy zenetörténet: plebsque] animetur ad opus pietatis et scandalum evitetur; obligabitur etiam cum reliquis musicis diligenter administrare musicam[,] et sine licentia nostra nullomodo se absentare, in 
Seit Hárichs Mitteilung, dass Schmidtbaur „aus einer in Wien bekannten Musiker Familie stammte“, hält man den Eisenstädter Musiker für einen Spross ebenjener angeblichen Wiener Musikerfamilie ${ }^{12}$. In Wirklichkeit waren aber weder er noch sein Bruder Johann Carl, der kaiserlich-königliche Hofmusiker, geborene Wiener. Laut des in St. Stephan in Wien angefertigten Heiratsprotokolls vom 24. Mai 1688 stammte Johann Carl Schmidtbaur aus Kirchberg (Kirchberg am Wagram), wo man ihn in den Kirchenmatriken tatsächlich findet ${ }^{13}$. Er ist geboren am 8. Februar 1662 als Sohn des dortigen Organisten-Schulmeisters (ludimagister, ludirector) und dessen Ehefrau Eva ${ }^{14}$.

In Eisenstadt taucht neben Franz Schmidtbaur noch ein weiterer Musiker namens Schmidtbaur auf, nämlich Ferdinand Schmidtbaur. Dieser „, fürst1[icher] Chor Musicus“ starb laut Todesprotokoll am 24. April 1687 im Alter von 27 Jahren in Eisenstadt ${ }^{15}$. Da der am 16. Januar 1658 in Kirchberg geborene zweite Sohn David Schmidtbaurs gleichfalls Ferdinand hieß ${ }^{16}$,

absentia vero nostra Parochi Arcensis licentia. Conabitur etiam musicam corralem augere et in componendo diligentiam exercere[,] et ad instrumenta chori diligenter attendere ne [Esterházy zenetörténet: de] alio quam ad officia Divina adhibeantur et servitia si opus foret [Esterházy zenetörténe: fuerit] nostra. Scholares vero quos committimus ipsi instruendos [Esterházy zenekar első karmestere: instrumendos] diligenter docebit, ut per illos magis possit augeri musica“"

${ }^{12}$ Johann Hárich, Inventare der Esterházy-Hofmusikkapelle in Eisenstadt, in: HJB IX., Wien 1975. S. 10.: „Schmidtbauer, der aus einer in Wien bekannten Musikerfamilie stammte“; Tank, Studien ..., op. cit. S. 55.: „entstammte aus einer Wiener Musikerfamilie“.; Ágnes Sas, (o.T., Einführung) in: Esterbázy Pál: Harmonia caelestis (1711). hrsg. von Ágnes Sas, (Musicalia Danubiana 10.) Budapest 1989. S. 14.: „kiterjedt bécsi zenészcsaládból származó" [,aus einer umfangreichen Wiener Musikerfamilie stammend“]; Kornél Bárdos, Fóúri zeneélet, [Musikleben des Hochadels] in: Magyarország zenetörténete, hrsg. von Kornél Bárdos, Bd. II. Budapest 1990. S. 122.: „bécsi zenész családból származó“ [,aus einer Wiener Musikerfamilie stammend"].

${ }^{13}$ Wien, St. Stephan, Pfarre, Trauungsmatriken, Bd. 29., S. 881: am 24. Mai 1688 heiratet Johan Carl Schmidtbaur „Kay[serlicher] Musicus“ und Maria Katharina Bauer, Tochter des Johann Christoph Bauer (vormals Verordneter beim Kärntnertor) und dessen Frau Anna Maria.

${ }^{14}$ Kirchberg, Pfarre, Taufen 1649-1670, S. 209.: „Dominus Jacob[us] Wenzhina vicarius Baptizavit, Joannem Carolum. Davidis Schmidpauers org[anisten] et ludim[agistri] in Khirchberg et uxoris eius Euae filium legitimum p[at]r[inus] H. Sebastianus Khlinglmair, markhtrichter ibidem".

15 André [Endre] Csatkai, Beiträge zur Geschichte der Musikkultur in Eisenstadt, Mitteilungen des Burgenländischen Heimat- und Naturschutzvereins. 5 (Eisenstadt 1931) Nr. 2. S. 22.; Nach Hárichs Musikerübersicht diente Ferdinand Schmidtbaur von 1678 bis 1687. Hárich, Esterházy Zenetörténet, op. cit. Heft III. S. 43.

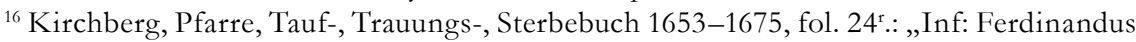




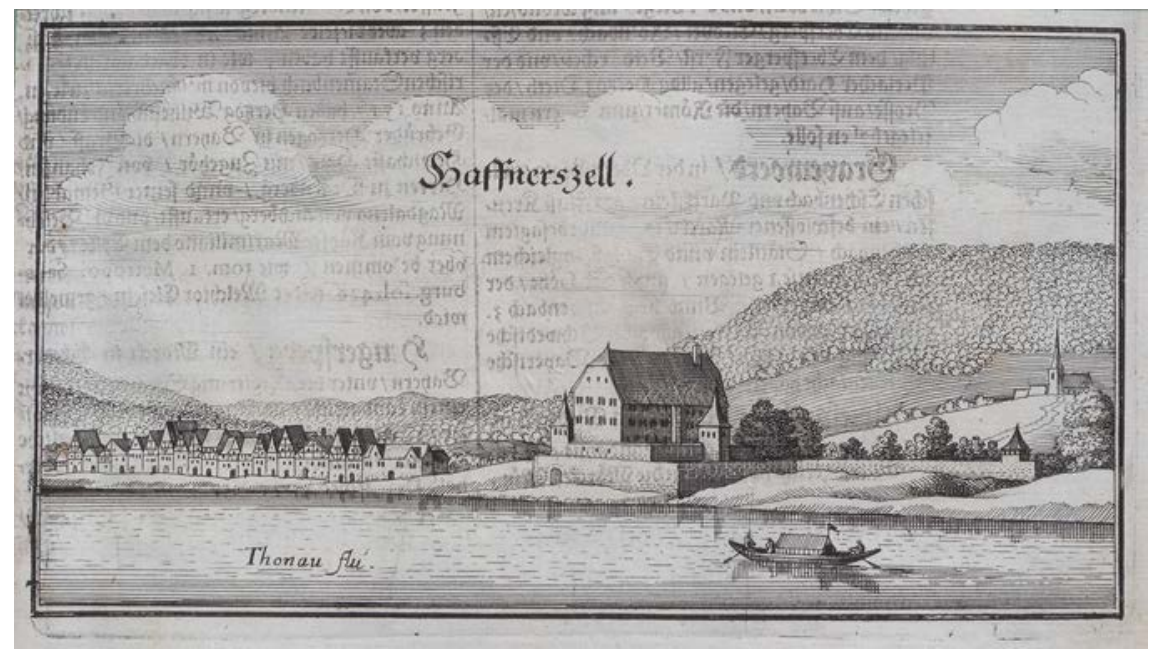

Abb. 1: Matthaeus Merian, Topographia Bavariae [...], 1644. Haffnerzell (Obernzell)

so ist anzunehmen, dass der in jungem Mannesalter in Eisenstadt verstorbene Musiker, Ferdinand Schmidtbaur der Bruder von Franz und Johann Schmidtbaur war, auch wenn Ferdinand zur Zeit des Todes schon einige Monate älter als 28 geworden war.

Im Gegensatz zu Ferdinand und Johann Carl Schmidtbaur ist in len Kirchberger Kirchenmatriken die Geburt des späteren Eisenstädter $=$ ens chori Franz Schmidtbaur nicht verzeichnet. Einem Missverständnis von Hárich folgend - wovon später noch die Rede sein wird - bezeichnet man Schmidtbaur heute als in Salzburg gebürtig. Dies trifft aber nicht zu. Seine Geburt lässt sich anhand der Matriken der Salzburger Dompfarre nicht ermitteln, und dort kommt merkwürdigerweise im in Frage kommenden Zeitraum der Familienname Schmidtbaur nicht einmal vor. Auf die richtige Spur führt die am 14. Juli 1676 geschlossene Heirat der jüngsten Schwester der Schmidtbaur Gebrüder, Barbara (Taufname: Rosina Barbara). In den Kirchberger Heiratsmatriken wird ihr Geburtsort mit Obernzell

Pr. David Schmidtbaur, organist und Schulmaister zu Khirchberg Mr. Eua Patrinus: Herr Sebastian Khlinghmaÿer markhtricht zu Khirchberg“; Hárich, Esterházy Zenetörténet, op. cit. Heft II. S. 46, bezeichnet ihn ohne Quellennachweis als jüngeren Bruder von Franz Schmitbaur. Das Ehepaar Schmidtbaur hatte noch einen weiteren Sohn, den in Kirchberg am 27. Februar 1660 geborene Sebastianus, der aber am 14. Februar 1663 schon als Kleinkind verstarb. Kirchberg, Pfarre, Tauf-, Trauungs-, Sterbebuch $1653-$ 1675, fol. 39v (Geburt) S. 53. (Tod). 
angegeben ${ }^{17}$. Dieser Hinweis hilft auch, den Geburtsort und das Geburtsdatum ihres Bruders, Franz Schmidtbaur, zu ermitteln.

Am 2. Mai 1650 registrierte man in Obernzell (genannt auch als Hafnerzell) bei Passau an der Donau die Heirat des „Organisten, schulmeister, vnd Marckht schreiber" David Schmidtbaur mit der aus der nahen Ortschaft Hauzenberg stammenden Eva Fri(e)d1 ${ }^{18}$. Hier in Obernzell ist als zweites Kind des Ehepaares am 19. September 1652 Franz geboren ${ }^{19}$ :

Pater David Schmidtpaur Schuelmeister, Organist, vnnd Marckh schreiber alhie

M[ate]r Eua

Infans Francisc[us]

Patrin[us] Georg Hazelstorfer Ratsbuerger, vnnd Hafner alhie

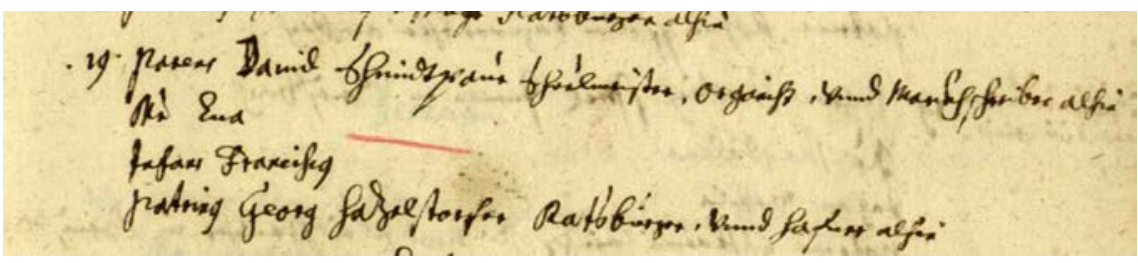

Abb. 2: Obernzell, Matrikeleintragung: Franz Schmidtbaurs Geburt

(Quelle: data.matricula-online.eu)

Obwohl in den einschlägigen Veröffentlichungen Schmidtbaurs Geburtsjahr mit 1649 angegeben wird, was man anhand jenes Alters von 52 Jahren errechnete, das anlässlich seines Todes in den Eisenstädter Kirchenmatriken vermerkt wurde, muss man jetzt feststellen, dass beide Angaben un-

${ }^{17}$ Kirchberg, Pfarre, Tauf-, Trauungs-, Sterbebuch 1676-1697, S. 5.: „Vonn ObernZell gebührtig, anitzo alhier zu Kirchberg“.

${ }^{18}$ Archiv des Bistums Passau, Obernzell, Trauungen 1649-1670, S. 437.: „In matrimoniu[m] gene[ros]i Honestu[m] et artificiosum Juvene[m] Davide[m] Schmidtpaur[,] Organisten, schulmeister, vnd Marckht schreiber alhie, cu[m] Honesta Virgine Eua[,] Honesti Adami Fridls Cive et pistoris in Hauzenberg et Mariae ux[ori] legitima filia. Testes Sponsi: Michael Herenbeckh Fürstl[icher] Marckhrichter vnndt Georg Hasslstorffer Raths buerger beede alhie [Testes] Sponsae Hanß Freÿ B[ürger] vnd schwarzstüeber [?], wie auch Hanß Maurer Markhtschreiber beede zue Hauzenberg“

19 Archiv des Bistums Passau, Obernzell, Taufen 1649-1670, S. 209. Das erste Kind, eine Tochter namens Anna Maria wurde am 28. Juni 1651 geboren. Ebda. Taufen 1649_ 1670, S. 197. Sie starb am 28. April 1673 in Kirchberg. Kirchberg, Pfarre, Pfarre, Tauf-, Trauungs-, Sterbebuch 1653-1675, S. 118. 
zutreffend sind. Franz Schmidtbaur ist erst drei Jahre später 1652 geboren, und zum Zeitpunkt des Todes war er im Alter von nur 49 Jahren.

Während die Hauzenberger Herkunft der Mutter belegt ist, bleibt die des Vaters unklar. Jedenfalls wird David Schmidtbaur im Heiratsmatrikel nicht als Bürger von Obernzell genannt. Daher könnte er kurz vor 1650 nach Obernzell/Haffnerzell gekommen sein ${ }^{20}$.

David Schmidtbaur und seine Familie verließen Obernzell nach einigen Jahren. Ab 1654 kann man ihn und seine Familie im Kirchberg am Wagram nachweisen ${ }^{21}$. Hier blieb er als Organist-Schulmeister bis zu seinem am 27. April 1663 erfolgten Tod. Laut Todesmatrikel soll er damals 32 Jahre alt gewesen $\operatorname{sein}^{22}$, was jedoch aufgrund seiner Heirat im Jahre 1650 wohl in Zweifel zu ziehen ist. Er wäre dann bei seiner Heirat im Jahre 1650 erst 18 oder 19 Jahre alt gewesen. Seine Geburt ist deshalb möglicherweise vor 1631 anzusetzen.

Nach dem Tod von David Schmidtbaur wurde seine Witwe Februar 1665 von dessen Nachfolger, Hanns Philipp Wachter, musicus Cantor bzw. ludimoderator und organista in Kirchberg geheiratet. Als Wachter recht jung schon September 1670 starb, ging sie im darauffolgenden Jahr die Ehe mit dem nachfolgenden Schulmeister-Organisten, Friedrich Stegmann ein ${ }^{23}$. Da ihre schon erwähnte Tochter, Barbara, 1676 Stegmans Bruder, Johann Christoph Stegmann, Kantor in Kirchberg, heiratete, wurden somit Mutter und Tochter gleichzeitig auch Schwägerinnen. Diese Heiraten zeigen die enge Verbindung innerhalb der kleinstädtischen Musiker-Intelligenz-

\footnotetext{
${ }^{20}$ Seine Geburt lässt sich in den Kirchenmatriken von Obernzell nicht finden, auch wenn der Name Schmidtbauer, der in der Region nicht selten zu sein scheint, selbst in Obernzell belegt ist. Archiv des Bistums Passau, Obernzell, Taufen 1629-1635.

${ }^{21}$ Nach Wilhelm Simlinger, Aus der Vergangenheit von Kirchberg, Altenwörth ... Ein Heimatbuch von Wilhelm Simlinger, Kirchberg 1958. wirkte David Schmidtbaur seit 1654 dort als Schulmeister. Dies lässt sich gegenwärtig nicht bestätigen, da die Magistratsprotokolle erst seit 1672 vorhanden sind. - Freundliche Mitteilung von Maria Knapp. In den Kirchmatriken wird Schmidbaur erst am 11. Januar 1656 erwähnt, „D. David Schmidtbaur organista et ludimag[iste]r“ als Trauzeuge für Johann Jacob Dotzauer (Dozauer) und Catharina Pichler. Kirchberg, Pfarre, Tauf-, Trauungs-, Sterbebuch $1653-$ 1675, S. 26.

${ }^{22}$ Kirchberg, Pfarre, Tauf-, Trauungs-, Sterbebuch 1653-1675, S. 53.: „Sepult: H: Dauidt Schmidwaur ludima[gister] et organista in Kirchberg Ann: 32“

${ }^{23}$ Kirchberg, Pfarre, Tauf-, Trauungs-, Sterbebuch 1653-1675, S. 134. Hanns Philipp Wachter starb am 12. September 1670 im Alter von 28 Jahren. Ebd. S. 105. Seine Witwe wurde am 11. Januar 1671. von Friedrich Stegmann geheiratet. Ebd. S. 216. Ihr Todeszeitpunkt konnte nicht ermittelt werden.
} 
schicht wie auch das Weiterleben der alten Tradition der Eheschließungen innerhalb von Berufsgruppen.

Angesichts der bis jetzt geschilderten familienkundlichen Dokumente lässt sich feststellen, dass die mehrmals wiederholte Behauptung, der Eisenstädter Regens chori Franz Schmidtbaur stamme aus einer Wiener Musikerfamilie, unzutreffend ist. Lediglich sein Bruder, Johann Carl, wurde Hofmusiker in Wien. Die Familie Schmidtbaur und ihre Musikersöhne haben aber in Wirklichkeit eine süddeutsche-bayerische bzw. oberösterreichische Herkunft.

Über die musikalische Ausbildung der Schmidtbaur Gebrüder ist nichts bekannt. Ob sie ihr Können und ihre Kenntnisse nur in der Obhut des Vaters erwarben, oder sich als Lehrlinge anderswo verdingten, darüber fehlen uns momentan die Quellen. Auffallend ist jedenfalls, dass zwei von ihnen, der älteste, Franz, und der jüngste, Johann Carl, Viola da Gamba spielten. Auch hatte dies der Sohn des Letzteren, Franz Anton als sein Hauptinstrument, der, laut einer durch einen Aktenvermerk vom 10. April 1699 übermittelten Aussage seines Vaters, „in seinen Jungen Jahren ein prodigio in der viola di gamba" sein sollte, und später von 1707 bis zu seinem Tod am 1. Dezember 1737 ebenfalls in der Wiener Hofmusikkapelle angestellt war ${ }^{24}$. Ob das Spielen der Viola da Gamba innerhalb der Familie Schmidtbaur auf eine besondere Veranlagung zurückzuführen sei, oder eher auf eine sonst nicht dokumentierte Familientradition, oder aber auf einen uns nicht bekannten Lehrmeister - lässt sich gegenwärtig nicht sagen.

Der jüngste der Söhne Schmidtbaurs, Johann Carl Schmidtbaur, war von Anfang 1682 bis zu seiner Pensionierung am 1. Oktober 1711 Mitglieder der kaiserlich-königlichen Hofkapelle. Er wurde offensichtlich als ein guter und universell einsetzbarer Musiker geschätzt, der als Gambist, Violinist, Instrumentist und Organist wirkte, darüber hinaus unterrichtete er am Hof

\footnotetext{
${ }^{24}$ Franz Anton Schmidtbaur wurde am 19. Juli 1689 geboren. Wien, St. Stephan, Pfarre, Taufbuch 1688-1689, S. 702.; Am 10. April 1699 Johann Carl Schmidbaur beantragt, dass sein Sohn, Franz Anton „für einen Scholarn in der viol di gamba“ aufgenommen werden soll, da er , in seinen Jungen Jahren ein prodigio in der viola di gamba sey, dan die Jenige, Welche schon Bey Jahren Weren, Unnd sich zu diesem instrument applicirt Hetten, schäzeten es für ihr gröstes glück, Wan Sie das praestieren Könnten, Was dießer Knab Thuet“. Herwig Knaus, Die Musiker im Archivbestand des Kaiserlichen Oberhofmeisteramtes, Bd. III. (Österreischische Akademie der Wissenschaften Philosophisch-Historische Klasse, Sitzungsberichte, Bd. 264) Wien 1969, S. 77.; Siehe noch Ludwig Ritter von Köchel, Die Kaiserliche Hof-Musikkapelle in Wien von 1543 bis 1867, Wien 1869. (Repr. Wiesbaden 1976) S. 70. Nr. 744.
} 
auf der Viola da Gamba einige Musiklehrlinge (scholar) ${ }^{25}$. Zu diesen gehörte auch sein Sohn, Franz Anton, für dessen Unterricht der Hof aufkam ${ }^{26}$. Das Ansehen von Johann Carl Schmidtbaur zeigt indirekt auch die Tatsache, dass der Hof beschwichtigend reagierte, als sich seine Schüler um 1700 über mangelnden Unterricht aufgrund seines damals schon bekannten angeschlagenen Gesundheitszustandes beschwerten, aber auch klagten: „die Zeit so er sich nimbt, wendet er zur instruction seines Sohns an“627.

Johann Carl Schmidtbaur war 20 Jahre alt, als er in die Wiener Hofkapelle aufgenommen wurde. Sein zehn Jahre älterer Bruder, Franz könnte in einem ähnlichen Alter gewesen sein, als er während der frühen 1670er Jahren nach Eisenstadt gekommen war ${ }^{28}$. Wann genau und auf welchem Wege die Verbindung zu Paul Esterházy zustande kam, ist unklar. Es ist eine grundsätzliche Frage, die sich bei vielen der damaligen Esterházy-Musiker stellt. Gegenwärtig ist es ein Rätsel, wie sie aus den zum Teil weit entfernten österreichischen und süddeutschen-bayerischen Gegenden nach Eisenstadt gefunden haben. Bei anderen benachbarten und mit Paul Esterházy verwandten ungarischen Magnaten (wie z.B. Ádám I. Batthyány, Ferenc III. Nádasdy) ist bekannt, dass sie in Wien Mittelsmänner hatten, die sich als informelle Musikagenten um Anwerbung von geeigneten Musikern bemühten ${ }^{29}$. Im Falle von Paul Esterházy weiß man jedoch nicht mal andeutungsweise von Ähnlichem.

Während die zur Verfügung stehenden Quellen über die Familienverhältnisse und über den Lebenslauf von Franz Schmidtbaur einiges hergeben, teilen die heute bekannten Dokumente kaum etwas über seine dienstlichen Aktivitäten in Eisenstadt mit. Diesbezügliche Schriftstücke der esterhá-

\footnotetext{
${ }^{25}$ Köchel, Die Kaiserliche Hof-Musikkapelle, S. 69. Nr. 718.; Knaus, Die Musiker, Bd. II. (Sitzungsberichte, Bd. 259) Wien 1968, S. 98, Knaus, Die Musiker, Bd. III. S. 53, 74, 77, 101, 126, 142.; Johann Carl Schmidbaur starb am 29. März 1714. Wien, St. Stephan, Pfarre, Barleihbuch 1714, fol. 41 ${ }^{\mathrm{r}-\mathrm{v}}$ : ,alt 53 Jahr“; bei Köchel, Die Kaiserliche Hof-Musikkapelle, S. 69. Nr. 718, wird irrtümlich ein Todesalter von 54. Jahren mitgeteilt.

${ }^{26}$ Knaus, Die Musiker, Bd. III. S. 77.

${ }^{27}$ Siehe die Beschwerden von Leopold von Ham (1701) und Caspar Wenger (1703): Knaus, Die Musiker, Bd. III. S. 101, 126.

${ }^{28}$ Harich dachte noch, dass Schmidtbaur 29 Jahre alt war, als er sich in Dienste Esterházys begab: Harich, Esterházy Zenetörténet, Heft II. S. 54.

${ }^{29}$ Peter Király, Wolfgang Ebner levelei Batthyány Ádámnak (1643-1650) [Wolfgang Ebners Briefe an Adam Batthyány] In: Magyar Zene, 39 (2001) Nr. 1, S. 85-98.; Peter Király, Musik und Musiker an der Residenz des Ferenc Nádasdy III. in: Die Familie Nádasdy vom 16. bis ins 20. Jahrhundert. Hrsg. von Rudolf Kropf (Tagungsband der 29. und 30. Schlaininger Gespräche 2009/2010. Wissenschaftliche Arbeiten aus dem Burgenland /WAB/ Band 154). S. 188-189.
} 
zyschen Hofhaltung fehlen fast gänzlich. Ausnahmen sind lediglich die Beförderungsurkunde von 1678 und ein wahrscheinlich ihn betreffendes Schreiben von Paul Esterházy aus dem Jahr 1686 - worauf noch zurückzukommen sein wird ${ }^{30}$. Dass Schmidtbaur bis zu seinem 1701 erfolgten Tode in Eisenstadt lebte und wirkte, lässt sich überhaupt nur anhand von Kirchenbucheinträgen und seines Nachlassinventars folgern ${ }^{31}$.

Angesichts der fast unüberschaubaren Menge von Quellenangaben, die aus der Zeit von Paul Esterházy über Musiker zur Verfügung stehen, erscheint diese Lückenhaftigkeit der Dokumentation im Bezug auf Schmidtbaur auf den ersten Blick überraschend, aber Tatsache ist, dass unsere Detailkenntnisse über Tätigkeit, Anstellungsdauer o.ä. von vielen Esterházy-Musikern trotz der Gesamtmenge an Informationen über Eisenstädter Hofmusiker meistens sehr bescheiden bleiben. Schmidtbaur stellt keineswegs einen Einzelfall dar, es gibt viele vergleichbare Fälle ${ }^{32}$.

Franz Schmidtbaur heiratete recht spät, erst im Alter von fast 38 Jahren am 18. Juli 1690 in Eisenstadt. Wie in den Kirchenmatriken zu lesen ist: „Contraxit Matrimonium der Edle gelehrte vnd Kunstreiche H[err] Franz

${ }^{30}$ Harald Dreo behauptete ohne Quellenhinweis: „Schmidtbauer wurde nicht als Kapellmeister, sondern als Organist und Chorleiter geführt". Diese Aussage lässtsich anhand der zur Verfügung stehenden Dokumente nicht belegen. Dreo, Die fürstlich Esterházysche Musikkapelle, S. 87-88.

31 11. Juli 1688. (Pate); 16. Juli 1690 (Heirat); 16. Oktober 1690 (Paten gemeinsam mit seiner Frau); 13. Mai 1691 und 11. Juli 1691 (Geburt und Tod von Paul Schmidtbaur); 10. Januar 1693 (Pate); 10. November 1697 (Pate); 29. März 1698. (Geburt von Johann Georg Schmidtbaur); 19. Juni 1700 (Geburt von Franz Anton Schmidtbaur) - All diese Angaben verdanke ich Josef Pratl (Eisenstadt), der mir die Schmidtbaur betreffenden Einträge der Schloßpfarre bzw. der Stadtpfarre sowohl in Transkription als auch als Bilder zur Verfügung stellte.; Das Nachlassinventar siehe: Hárich, Esterházy Zenetörténet, Heft II. S. 93-98.

${ }^{32}$ Hier sollte ein Hinweis auf die Familie Lindt als Beispiel genügen: Eine von Josef Pratl veröffentlichte Anweisung Esterházys vom Frühjahr 1710 belegt, dass er um diesen Zeitpunkt (und nicht 1711!) Ferdinand Andreas Lindt und seine sieben Kinder in seinen Diensten aufgenommen hat. Trotzdem tauchen in den erhaltenen Rechnungen die Lindts mit einer Ausnahme nicht auf. Lediglich die Sängerin Antonia Lindt wird im Conventional des Jahres 1713 unter den Musikern aufgelistet. Obwohl alle Lindts bis Ende ihres Leben in Eisenstadt wirkten, werden sie erst nach Paul Esterházys Tod in den Hofdokumenten greifbar. Interessanterweise, behaupten aber die Lindt-Kinder in einem wahrscheinlich im Herbst 1721 gestellten Antrag, dass sie Paul Esterházy sieben Jahre lang dienten, was angesichts des Todes des Fürsten im Jahre 1713 entweder einfach nicht wahr ist, oder aber sie haben vor 1710 schon vier Jahre lang Esterházy musikalisch gedient, was momentan nicht zu belegen ist. Siehe: Pratl/Forchtenstein, (EHB 7) S. 33.; Der Antrag von ca. 1721 wurde schon von Hárich transkribiert. Hárich, Esterházy zenetörténet, op. cit. Heft VI. S. 54-57. Er wird auch kurz erwähnt in Pratl/Forchtenstein, (EHB 7), S. 33. Anm. 63. 
Schmidtpaur noch lediges Standtß Ihro Hochfürstl[icher] G[naden] Pauli Esterhasy wohl meritierter Regens Chori“" mit Susanna (Susanna Clara) Leeb „weyl[and] H[err] Hanß Leeb Seel[igen] vnd seiner Hinterlassenen Wittib Magdalena beed[er] Eheleiblich erzeügte Tochter“. Die gesellschaftliche Stellung des Ehepaares machen uns die Trauzeugen deutlich: seitens des Bräutigams wurde die Ehe von zwei Hofmusikern, Johann Georg Hörger Organist und Paul Faber „,musicus“ bekräftigt, seitens der Braut dagegen vom Vater des Organisten, von Andreas Hörger, „deß Innern Rathß Senior", der 1689 und 1694 das Amt des Königrichters versah, sowie von dem Kürschner Adam Lehner ${ }^{33}$.

In den musikwissenschaftlichen Veröffentlichungen geistert eine angebliche weitere Eheschließung von Schmidtbaur. Diese basiert jedoch auf dem schon angesprochenen Missverständnis von Hárich. Endre Csatkai, der große Forscher der Sopron/Ödenburger Region, veröffentlichte nämlich, dass in Eisenstadt im Jahre 1697 der aus Salzburg stammende Franz Schmidthammer die Tochter des Münchener Musikers Johann Pichler heiratete. Diese Mitteilung veranlasste Hárich zu der Annahme, dass Csatkai den Namen falsch gelesen hätte und sich die Angabe in Wirklichkeit auf den Regens chori Franz Schmidtbaur bezog ${ }^{34}$. Dadurch wurde aus Schmidtbaur ein angeblicher Salzburger und Hárich machte ihn auch noch um eine Phantomehe reich Beide Folgerungen sind aber unzutreffend: der Geburtsort der Regens = ri lautete - wie schon dargestellt - anders, nämlich Obernzell/ Hafnerzell, außerdem hat er 1697 nicht geheiratet. Seine Frau, Susanna Clara Leeb, überlebte ihn als Witwe - was übrigens Hárich sehr wohl bekannt war.

Das erste Kind des Schmidtbaur-Ehepaares, Paul - der seinen Vornamen offensichtlich nach seinem Taufpaten, dem Hofmusiker Paul Faber erhalten hat - wurde am 13. Mai 1691 getauft $^{35}$. Er starb aber schon am 11. Juli desselben Jahres. Ein zweiter Sohn, Johann Georg wurde am 29. März 1698 geboren, und darauffolgend am 19. Juni 1700 kam der dritte Sohn, Franz Anton. Diese

33 „18. Contraxit Matrimonium der Edle gelehrte vnd Kunstreiche H[err] Franz Schmidtpaur noch lediges Standtß Ihro Hochfürstl[icher] G[naden] Pauli Esterhasy wohl meritierter Regens Chori mit der Tugentsam[en] Jungfrau Susanna Leebin, weyl[and] $\mathrm{H}[\mathrm{err}] \mathrm{Han} \beta$ Leeb Seel[igen] vnd seiner Hinterlassenen Wittib Magdalena beed[er] Eheleiblich erzeügte Tochter. Testes ex site Sponsi H[err] Johann Geörg Hörger vnd H[err] Paul[us] Fabri beede Fürstliche Musici, ex site Sponsae der Edl feste vnd gelehrte $\mathrm{H}[\mathrm{err}]$ Andreaß Hörger deß Innern Rathß Senior vnd H[err] Adam Lehner Kirschner allhier.“ - Freundliche Mitteilung von Josef Pratl.

${ }^{34}$ André [Endre] Csatkai, Die Beziehungen Gregor Josef Werners, Joseph Haydns und der fürstlichen Musiker zur Eisenstädter Pfarrkirche, Burgenländische Heimatblätter 1(1932) S. 14; Hárich, Esterházy zenetörténet, Heft II. S. 54.

${ }^{35}$ Dreo, Die fürstlich Esterházysche Musikkapelle, S. 87. 
beiden sind auch als Erben in dem im Sommer 1701 erstellten Nachlassinventar von Franz Schmidtbaur festgelegt $t^{36}$. Franz Anton jedoch, wie schon das erste Kind, starb sehr früh, er wurde am 16. November 1702 beerdigt $^{37}$.

In den Eisenstädter Kirchenmatriken von 1701 steht: „Den 22. Märtj ist Herr Franz schmidtbaur fürstl[icher] Regens Chori gestorben, undt mit 52 iahren alt begraben worden “38. Wie schon vorher erklärt, stimmt das hier angegebene Alter nicht, der Verstorbene war nicht mal 50 Jahre alt. Das am 6. August aufgenommene „Inventarium über wayl[and] nach ableben Herrn Franz Schmittpaurn, seel[igen] gewesten fürstl[ichen] Regens Chory Zeitl[iche] verlassenschaft ${ }^{\text {‘39 }}$ zeigt, dass Schmidtbaur in einem eher bescheidenen Wohlstand lebte. Er besaß in Schlossnähe „aine Behausung im Schlos Mayrhoff [= Meierhof beim Schloss] liegent" - es wird 1707 als „Heysl“ bezeichnet -, sowie außerhalb der Stadt einen „Weingarten in Sandtgruben“. Diese Immobilien wurden auf 100 fl. bzw. 35 fl. geschätzt. Das Inventar listet Silbergeschmeide im Gesamtwert von 41 fl. $36 \mathrm{kr}$ auf: „32 Lath Silberne Knopf“, geschätzt auf 19 fl. 12 kr; ,ain Silber giertl mit 9 Lath“, 5 fl. 24 kr; ,2 Silber Löffel, sambt ain Mösser und Gapel mit silbern Schallen“, 3 fl.; ,ain Peten geldt mit 19 gross und klainen stukhen, sambt drey Stainen mit silber eingefast, eingefasste reliquien, und ain eingefasster Wolffs Zandt“, $14 \mathrm{fl}$. Außerdem fand man ,vüer gultene Ringl, ainer mit 4 Robindl, der 2te mit ain Waisl, der 3te Soria, der 4te mit ain diemant zusamben pr. 16 [f.].". Es wurden noch einige Kupfer- und Zinngegenstände registriert, sowie „Aller Handt Haussrath“, was man nicht einzeln auflistete. Bei den Textilien verdienen „2 Röckh und 2 Cämissoll mit Silbern Schlingl“ die Aufmerksamkeit. Darüber hinaus fand man noch „9 auf Leinbath gemahlter Bilter pr 6 [fl.]" wobei man die dargestellten Themen unerwähnt gelassen hat. Im Nachlassinventar von Franz Schmidtbaur sind weder Musikinstrumente noch Musikalien aufgelistet, und auch keine Bücher. Die ganze Hinterlassenschaft wurde auf 310 fl. 36 kr. 20 d. bewertet ${ }^{40}$. Dies entsprach ungefähr einem zweieinhalbjährigen Gehalt Schmidtbaurs als Leiter des Musikensembles. 1678 stand ihm neben Verpflegung an der

\footnotetext{
${ }^{36}$ Hárich, Esterházy Zenetörténet, Heft II. S. 93-98.

${ }^{37}$ Freundliche Mitteilung von Josef Pratl.

${ }^{38}$ Ebenda.; Dreo, Die fürstlich Esterházysche Musikkapelle, S. 88; Tank, Studien, S. 56.

${ }^{39}$ Hárich, Esterházy Zenetörténet, Heft II. S. 93-98.

${ }^{40}$ Wesentlich höher als Schmidtbaurs Nachlass wurde der Nachlass des 1692 gestorbenen Eisenstadter Goldschmidts Stefan Jagschitz bewertet. Er sollte nach Abzug seiner Schulden und der Gebühren noch immer 1408 fl. 39 kr. wert sein. Siehe: Harald Prickler, Das Goldschmiedehandwerk im burgenländischen Raum bis ins 19. Jahrhundert, In: Forscher - Gestalter - Vermittler, Festschrift Gerald Schlag (Wissenschaftliche Arbeiten aus dem Burgenland, WAB, Band 105) Eisenstadt 2001, S. 293.
} 
Tafel der Chormusiker 130 fl. in Barzahlung zu, und diese Summe blieb während seiner Dienstzeit entweder unverändert, oder wurde höchstens geringfügig erhöht. Jedenfalls bekam sein Nachfolger, Franz Rumpelnig im Jahre 1702 als Gehalt 150 fl. ${ }^{41}$.

Wahrscheinlich unterrichtete Franz Schmidtbaur den Fürsten früher schon davon, dass sein Bruder zur Wiener Hofkapelle gehörte und er dort auch Gambenunterricht gab. Wohl deswegen vereinbarte Paul Esterházy am 1. Januar 1705 mit Johann Carl Schmidtbaur, dem „des Römischen Reichs Cammer Musico“, dass er Hans Georg Schmidtbaur, „auf dem Viola di Campa instruieren“" soll, ,,auch in Betrachtung dass gemelter Knab seines lieben Bruders Sohn ist". In dem in Eisenstadt datierten Vertrag wurde außerdem noch festgelegt, dass sein Onkel Hans Georg, der damals etwas älter als sieben Jahre war, ,,auch lesen undt schreiben lehrnen lassen“ sollte ${ }^{42}$. Fraglich bleibt, wie viel Unterricht im Viola da Gamba-Spiel ihm Johann Carl Schmidtbaur überhaupt geben konnte, denn er war - wie vorher erwähnt - spätestens um 1701 schon „bekanntlich“ sehr krank ${ }^{43}$. In einer am 21. Februar 1713 vor Zeugen verfassten Urkunde beklagte er seine seit Jahren andauernde „müehe seliger bethlagerung“ und dass er ,,in disen seinen Gefährlich undt armselig[en] zue standt" auf die aufopferungsvolle Hilfe seiner Frau angewiesen $\mathrm{sei}^{44}$. Was also Hans Georg Schmidtbaur von seinem Onkel letztlich lernen und dadurch im späterem Leben erreichen konnte, ist unklar. Hans Georgs Lebenslauf bleibt nach 1705 vorerst unbekannt.

\footnotetext{
${ }^{41}$ Harald Prickler, Kleiner Beitrag zur Eisenstädter Musikgeschichte unter Paul Esterházy, in: Burgenländische Heimatblätter 30 (1968), S. 140.

${ }^{42}$ Hárich, Esterházy Zenetörténet, op. cit. Heft II. S. 87-88.; Unterricht „in literis“ wurde auch in dem zwischen Esterházy und Johann Joseph Fux am 1. Juni 1707 in Wien wegen das Unterrichts zweier junger Kastraten beschlossenen Vertrag vorgeschrieben. Budapest, Országos Széchényi Könyvtár, Zenemútár, Acta musicalia, Nr. 4035.; Vollständige Übertragung in: Hárich, Esterházy zenetörténet, op. cit. Heft III. S. 57-58.; Tank, Studien, S. 59, 64-65.

${ }^{43}$ „Knaus, Die Musiker, Bd. III. S. 101, 126.

${ }^{44}$ Quelle wie Anm. 2.: „daß Er von seiner liebsten Ehe consortin in seiner 22. Jähr[igen] Contractus und müehe seliger bethlagerung nicht allein sehr grosse von einer Ehe Gattin fast nicht erforder[liche] Warthe vnd Bedienung, Sond[er]en annebens auch Nahmhaffte undt über Fünff taußent gulden auß Tragende Geldt Posten (so sie mitelß ihrer, vnd ihrer frau Muetter Kunst reicher[,] nacher Hoff- undt anderwerthß Verkhauffter Handt arbeith erwenen) empfangen, und theilß zu seiner leider geneßung, theilst in die Würtschafft verwendet habe [...]Er H[er]r Schmidtbauer zu seiner Eheliebsten daß Vertrauen sezet, daß selbe mit der ihme so Geraumbe Zeit hindurch erwißener Treue continuiern, und in disen seinen Gefährlich undt armselig[en] zue standt Biß an sein Endte nicht Verlass[en] wede“.
} 
Am 1. Juli 1678 verordnete Paul Esterházy mit der Beförderungsurkunde auch, dass Franz Schmidtbaur auf Verlangen des Grafen Musikunterricht geben sollte ${ }^{45}$. Schüler von Schmidtbaur sind heute nicht bekannt. Das Ereignis, das am 8. Oktober 1686 den in Wien weilenden Paul Esterházy dazu veranlasste, den Schlosspropst anzuschreiben, der den Grafen bei seiner Abwesenheit vertrat, könnte mit Schmidtbaur und einem Schüler in Zusammenhang gestanden sein. Wie in diesem Brief zu lesen ist, hat nach seinen Informationen der „Gambista“ dem Geiger Ferdinand Nigrini mit dem Tod gedroht. Hárich identifizierte den streitenden Gambisten - wohl zu Recht - mit Franz Schmidtbaur, und folgerte, dass der Streit wegen Diskantisten ausgebrochen sei, deren alleinigen Unterricht durch Nigrini Paul Esterházy im weiteren Verlauf des Briefes bekräftigte ${ }^{46}$.

Wie es scheint, war Paul Esterházy im Großen und Ganzen mit Franz Schmidtbaur zufrieden. Er wies in dem mit Johann Carl Schmidtbaur beschlossenen Unterrichtsvertrag von 1705 darauf hin, dass dessen Bruder „bis $30 \mathrm{Jahr}$ lang treue dienst geleistet" hat, und sich ebenso auf diese Tatsache berufend (,,in ansehung ihres Manns seiner Uns treu gelaisteten Diensten“) hat er am 29. Dezember 1707 die sonst fällige Taxe der inzwischen wieder verheirateten und nach Loretto umgezogenen Witwe von Schmidtbaur erlassen, als sie das „Heysl in Schloss Mayrhoff“ verkauft hatte ${ }^{47}$.

Nach Feststellung der ungarischen Musikhistorikerin Ágnes Sas, die die Neuausgabe der 1711 von Paul Esterházy veröffentlichten (jedoch offensichtlich nicht von ihm selbst komponierten oder musikalisch bearbeiteten) Sammlung „Harmonia caelestis“ betreute, sollte man in der Person von Franz Schmidtbaur den möglichen, oder sogar wahrscheinlichen Helfer des Fürsten vermuten, der an der Erstellung der „Harmonia caelestis“ teilgenommen hat ${ }^{48}$. Dass man Schmidtbaur die bis 1699 abgeschlossene Vorarbeit zuschreiben sollte, ist wohl eine berechtigte Folgerung, und zwar auch dann, wenn die für die „Harmonia caelestis“ kennzeichnende stilisti-

\footnotetext{
${ }^{45}$ Hárich, Esterházy zenetörténet, Heft II. S. 90., „Scholares vero quos committimus ipsi instruendos diligenter docebit, ut per illos magis possit augere musica“

${ }^{46}$ Hárich, Esterházy zenetörténet, Heft II. S. 51, 86-87.: „Gambista quoque (uti informamur) ipsi Nigrino mortem minatur quod si ita est, admoneat ipsum serio Nomine Nostro, dicatque eidem ut a similibus minis se se abstineat, nec amplius ullius rixa fomes esse velit, alias experietur is quoque id, quod nunquam sperasset. Quoad Discantistas, sic nos resolvimus, Discantistae omnino fidicini Nigrinio subsint, instruanturque ab eodem, omnemque dependentiam ab ipso habeant, nec volumus absolute, ab aliis dependeant.“

${ }^{47}$ Hárich, Esterházy Zenetörténet, Heft II. S. 98.

${ }^{48}$ Sas (o.T., Einführung) in, Esterházy Harmonia caelestis, S. 15.: „a herceg lehetséges sőt valószínű - segítőtársát“.
} 
sche Vielfalt die Annahme mehrerer - vielleicht nicht gleichzeitiger - Mitwirkender nahe legt.

Jedenfalls wurde in der Beförderungsurkunde von 1678 festgelegt, dass Schmidtbaur fleißig komponieren sollte. Seine diesbezügliche Aktivität könnte trotz dieser Verordnung nicht besonders umfangreich gewesen sein. Erhaltene Kompositionen von ihm sind so weit nicht bekannt. Es lassen sich heute lediglich anhand von Noteninventare einige Werke nachweisen, die wohl ihm zuzuschreiben sind.

In dem ersten überlieferten Noteninventar der Familie Esterházy, das die in der Eisenstädter Schlosskapelle vorhandene geistliche Musik auflistet, und das nach dem im März bzw. im Juni 1721 in kurzer Zeit sukzessive eingetretenen Tod der Familienoberhäupter Michael Esterházy und Josef Simon Anton Esterházy aufgenommen wurde, werden vier Kompositionen mit dem Namen Schmidtbaur verzeichnet. Drei davon tauchen auch in einem von Gregor Josef Werner angefertigten Inventar von 1737 auf.

1721, Ordentliche Beschreibung und Jnventierung Fürst Esterhazyschen Gschloß Eysenstatt, und deren darinnen sich befindenten Mobilien und Farnussen, wie solche den 24. Martij und 7. Junij 1721 als nach den zeitl[ichen] hindritto, Erstl[ich] Wayl[and] Fürst Michaele, und lestl[ich] Fürst Joseph bey der hochseligsten gedächtnus befunden worden:

Modetae ... „No. 5. Modet [Motette] de ressurec[tione] Dni. â 7 A[utore] Schmidpauer"

Alma Redemptoris ... „No. 12. â 6 Authoris Schmitbaur“

Regina coeli ... „Nr. 12. â 6 A[utore] Schmidpauer“

Regina coeli ... „Nr. 18. â 8 A[utore] Schmidpauer“ ${ }^{649}$

1737, Catalogus rerum musicalium in choro Kismartoniensi existentium per Dominum Gregorium Werner Suae Celsitudinis Capellae Magistrum confectus. Anno 1737:

„Alma [redemptoris] à 4 voc: Schmitpaur (†)“

„Regina [coeli laetare] à 4. Auth[ore] Schmitpaur (†)“

„Regina à 4. de Eodem ( $\dagger)^{\text {“50 }}$

49 Johann Hárich, Über das Schloß Esterhazy zu Eisenstadt und die Burg Forchtenstein Unbekannte Archivdokumente, Burgenlandische Heimatblätter 34 (1972) nr. 4. S. 163, 165; Hárich, Inventare der Esterházy-Hofmusikkapelle ..., op. cit. S. 15, 18.; Nach Dreo, Die fürstlich Esterházysche Musikkapelle ..., op. cit. S. 88. Alma Redemptoris und die erste Regina coeli ist „a 7“. Dreo scheint sich aber auf eine andere Quealle als Hárich berufen zu haben. Siehe: Dreo op. cit. S. 111. Anm. 31, er weist hier auf Protocollum Inventationis tempore incepti Tutoratus, Esterházy Archiv, Eisenstadt, Prot-Nr. 6022 hin. ${ }^{50}$ Budapest, Országos Széchényi Könyvtár (im Weiteren: OSzK), Acta musicalia 4251; 
Die abweichenden Stimmenangaben der Auflistungen sind wohl damit zu erklären, dass die Ersteller des Inventars von 1721 sowohl die Gesangstimmen als auch die Instrumentalstimmen zusammengezählt haben, wogegen Werner nur die Anzahl der Gesangsstimmen vermerkte. Obwohl in beiden Inventaren der Vorname von Schmidtbaur nicht angegeben wird, und ein bedeutender Anteil der 1721 inventarisierten Noten erst um 1715 durch Zukauf in den Besitz der Esterházy gelangten ${ }^{51}$, ist in der gegebenen Situation die Annahme vermutl ${ }^{-}$- doch berechtigt, dass man mit Schmidtbaur den früheren Eisenstädter ons chori Franz Schmidtbaur identifiziert.

Der in Ungarn vielerorts aktive Jesuitenpater Ignatius Müllner (1678 - † 25. August 1750, Sopron/Ödenburg) besaß eine umfangreiche Notensammlung, worin auch einige Werke von Musikern zu finden waren, die in Eisenstadt wirkten. Aus der Zeit von Paul Esterházy sind es Schmidtbaur, Prustman und Rumpelnig, aus der späteren Epoche Zivilhofer, Werner und Novotny. Die Sammlung selbst ist nicht erhalten, nur das von Müllner angefertigte Noteninventar existiert. Von Schmidtbaur besaß Müllner nur eine einzige Komposition: „Ave Regina“ „A 4. Vo. 2. VV 3 Tromb 4 Rip.

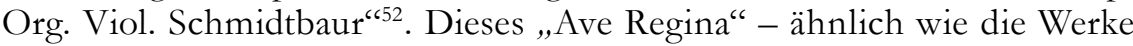

Hárich, Inventare der Esterházy-Hofmusikkapelle, S. 26.; Nach Hárich, Esterházy zenetörténet, op. cit. Heft II. S. 49. waren alle drei Kompositionen für vierstimmigem Chor mit Orchesterbegleitung („mindhárom kompozíció négyszólamú vegyeskarra, zenekari kísérettel").

${ }^{51}$ In voller Länge mitgeteilt von Hárich, Über das Schloß Esterhazy zu Eisenstadt, S. 162-166, und in: Inventare der Esterházy-Hofmusikkapelle, S. 13-20. Das Verzeichnis von 1721, das mehrheitlich Werke von Komponisten auflistet, die um die Mitte des 17. Jhs. in Wien aktiv waren, wird heute so interpretiert, dass es Musikalien aus der Zeit von Paul Esterházy enthält, und somit die Eisenstädter Hofmusik seiner Epoche repräsentiert. Doch ein bedeutender Teil der Noten wurde wohl erst 1715 von seinem Sohn Michael angeschafft. Michael Esterházy ließ am 5. Februar $1615=$ nceslaus (Wenzel) Zivilhoffer 100 fl., also eine recht große Summe, auszahlen, „unseren Cappel Maÿster vor unterschidtl[iche] erkauffte Musicalien welche wür ainzig undt allein zu Gottes Ehr unserer alhiesig[en] Schloß Cappeln biß fernerer unsere disposition gewipnet [gewidmet] seynt“. Wie es im Weiteren hieß: „Dieße Musicalia sollen in dem Schloß Capel buch eingetraget werdten, zue künftiger Nachricht." Sie wurden mit den vermutlich schon vorhandenen anderen Noten dann 1721 inventarisiert. Wie viele der aufgelisteten Titel letztlich aus der Zeit von Paul Esterházy stammen und wie viele von Zivilhoffer zugekauft wurden, lässt sich nicht beantworten. Die Zahlungsanweisung von Michael Esterházy, (Budapest, OSzK, Acta musicalia, Nr. 3953) wurde mit einigen Lesefehlern und ohne die darauf befindliche Quittung von Zivilhofer übertragen in: Hárich, Esterházy Zenetörténet, Heft VI. S. 52-53.

${ }^{52}$ Budapest, Egyetemi könyvtár, Kézirattár, F. 31. (spätere Bleistiftpaginierung) S. 34. nr. 16.; Zur Quelle siehe: Klára Rennerné Várhidi, Buda zenei élete a XVIII. században 
von Prustman und Rumpelnig - gehört auch zu dem um 1711 inventarisierten Grundbestand der Notensammlung, die Müllner danach offensichtlich bis kurz vor seinem Tod erweiterte und pflegte ${ }^{53}$. Da 1703 der Jesuitenpater ein Jahr in Ödenburg verbrachte ${ }^{54}$, ist zu vermuten, dass er entweder dort, oder in dem nicht weit entfernten Eisenstadt die Stücke von Schmidtbaur, Prustman und Rumpelnig erhalten hat. Müllner gibt in seinem Noteninventar nur selten Vornamen an, daher ist es auch in diesem Fall nur eine Annahme - vor allem wegen der anderen Esterházy-Musiker -, dass das besagte „Ave Regina“ eine Komposition von Franz Schmidtbaur war.

\section{FALSCHE ZUSCHREIBUNGEN:}

Nach dem 1714 eingetretenen Tod von Edmund Senmillner, Prior des Benediktinerklosters von Michaelbeuern bei Salzburg, listete man die Musi-

jezsuita források tükrében, [Das Musikleben von Buda im 18. Jh. im Spiegel der Jesuitenquellen] Teil I, in: Zenetudományi Dolgozatok 1988. Budapest 1988, S. $115-$ 119.; Katalin Szacsvai Kim, Das Noteninventar des Jesuitenpaters Ignatio Müllner. Ein Musikalienkatalog aus der ersten Hälfte des 18. Jahrhunderts, in: Oberschwäbische Klostermusik im europäischen Kontext. Alexander Sumski zum 70. Geburtstag, hrsg. von Ulrich Siegele, Frankfurt a. M. 2004, S. 43-66.

${ }^{53}$ Als Titelblatt findet man eine Anweisung von Müllner womit er das mögliche spätere Schicksal seiner Sammlung regelt. Darunter steht als Datum das Jahr 1711. Müllner hat das Inventar seiner Sammlung um 1711 offensichtlich in relativ kurzer Zeit erstellt. Dies belegt das einheitliche Schriftbild, das für die meisten Einträge kennzeichnend ist, sowie die bei diesen zu beobachtende gleichbleibende grauschwarze Tintenfarbe. Müllner hat wohl bis Ende seines Lebens das Inventar seiner Sammlung gepflegt. Er hat es mit neueren Erwerbungen erweitert, und strich diejenigen Titel, die er weggegeben hat. Auch korrigierte er falsche Titel- oder Autorenangaben. Verso steht auf der Titelseite eine Auflistung der Komponisten („Nomina Authorum hoc libro contentorum“). Hier lässt sich sehr genau unterscheiden, welche Komponisten bereits 1711 mit Werken in Müllners Sammlung vertreten waren, und welche später dazugekommen sind, wie z.B. Biechteler, Hasse, Vivaldi, oder die späteren Esterházy-Musiker Zivilhoffer, Werner und Novotni. Diese und einige weitere wurden nachträglich eingetragen, meistens irgendwo eingeschoben oder am Seitenrand dazu geschrieben, außerdem mit andersfarbiger Tinte bzw. schon mit etwas geänderter Handschrift. Die Werke von Schmidtbaur, Prustman und Rumpelnig gehörten alle zu dem um 1711 inventarisierten Grundbestand. Dies belegt sowohl das Schriftbild wie die Tintenfarbe, aber auch die Tatsache, dass in „Nomina Authorum" ihre Namen der alphabetischen Reihenfolge entsprechend eingereiht sind.

${ }^{54}$ Die Aufenthaltsorte von Müllner vor 1711: 1701, Leoben; 1702, Wiener Neustadt; 1703, Sopron/Ödenburg; 1704-1707, Wien; 1708, Judenburg; 1710-1711, Leoben; Siehe Rennerné Várhidi, Buda zenei élete a XVIII. században jezsuita források tükrében, S. 116. Anm. 50. und Katalin Szacsvai Kim, A jezsuita központok zenei élete a 18. századi Magyarországon, [Das Musikleben der Jesuitenzentren in Ungarn im 18. Jh.] in: Zenetudományi dolgozatok 2006-2007. Budapest 2007. S. 51. 
kalien des Klosters auf. Im Verzeichnis werden auch zwei Werke von einem gewissen Schmidtpauer erwähnt. Eine „Missa S. Joan: Baptistae. Segre J. Schmidtpauer“ und unter die Vespern „Beatus vir a 9 Sigre Schmidtpauer ${ }^{\ll 55}$. Da bei dem ersteren der Vorname des Komponisten mit J. abkürzt wurde, und die Messe Johannes dem Täufer gewidmet war, so ist wohl eine zutreffende Folgerung, dass es sich dabei um einen Komponisten namens Johannes Schmidtbaur handelte und nicht um Franz Schmidtbaur, auch wenn diese Fehlzuweisung in der einschlägigen Fachliteratur auftaucht ${ }^{56}$. Ob der genannte Johannes Schmidtpaur mit dem Bruder des Eisenstädter Musikers, Johann Carl Schmidtbaur identisch war, bleibt noch zu klären ${ }^{57}$.

Hárich nahm auch an, dass einige in Göttweig aufbewahrte und mit dem Nachnamen Schmidtbaur gekennzeichnete Kompositionen (6 antifona, 6 Ave Regina, 1 offertorium, 7 Regina Coeli und „Missa Neonati Coeli Pricipis") Franz Schmidtbaur zuzuschreiben wären ${ }^{58}$. Nach Meinung von Ágnes Sas sind die in Wilhering und Göttweig erhaltenen, nur mit Familiennamen versehenen, zwischen 1740-1745 und 1759-1820 kopierten bzw. aufgeführten Werke jedoch zu spät, als dass man sie für Kompositionen des 1701 gestorbenen Eisenstädter Schmidtbaur halten könnte ${ }^{59}$. Anfänglich behauptete Hárich zwar auch, dass die unter den fürstlichen Musikalien in Eisenstadt vorhandenen, mit Schmidtbauer gekennzeichneten, zwei Kurzmessen in G- bzw. D-Dur von Franz Schmidtbaur sind, später revidierte er jedoch diese Aussage und schrieb beide Joseph Aloys Schmidtbauer (1718-1809) $\mathrm{zu}^{60}$. Harald Dreo, sich auf das Noteninventar von 1858 berufend, benennt den Komponisten beider Messen (Inv. Nr. 1390 und 1391) zwar auch als Franz Schmidtbauer, doch er hält diese auch für spätere Kompositionen ${ }^{61}$.

\footnotetext{
${ }^{55}$ Hellmut Federhofer, Zur Musikpflege im Benediktinerstift Michaelbeuern (Salzburg), in: Festschrift Karl Gustav Fellerer zum. 60. Geburtstag ..., hrsg. von Heinrich Hüschen, Regensburg 1962, S. 109., 116.

${ }^{56}$ Siehe: Szacsvai Kim, Das Noteninventar, S. 64.

${ }^{57}$ Seine Aktivität als Komponist ist bis jetzt nicht belegt.

${ }^{58}$ Hárich, Esterházy zenetörténet, Heft II. S. 49.

${ }^{59}$ Sas, Esterházy Harmonia caelestis, S. 15.

${ }^{60}$ Hárich, Az Esterházy-zenekar első karmesetere, op. cit. S. 26.: „szerzeményei közül csak két kis mise (G- és D-dur) maradt fenn a hercegi kótatárban“; Hárich, Esterházy zenetörténet, op. cit. Heft II. S. 50.

${ }^{61}$ Dreo, Die fürstlich Esterházysche Musikkapelle, S. 111. Anm. 32.
} 


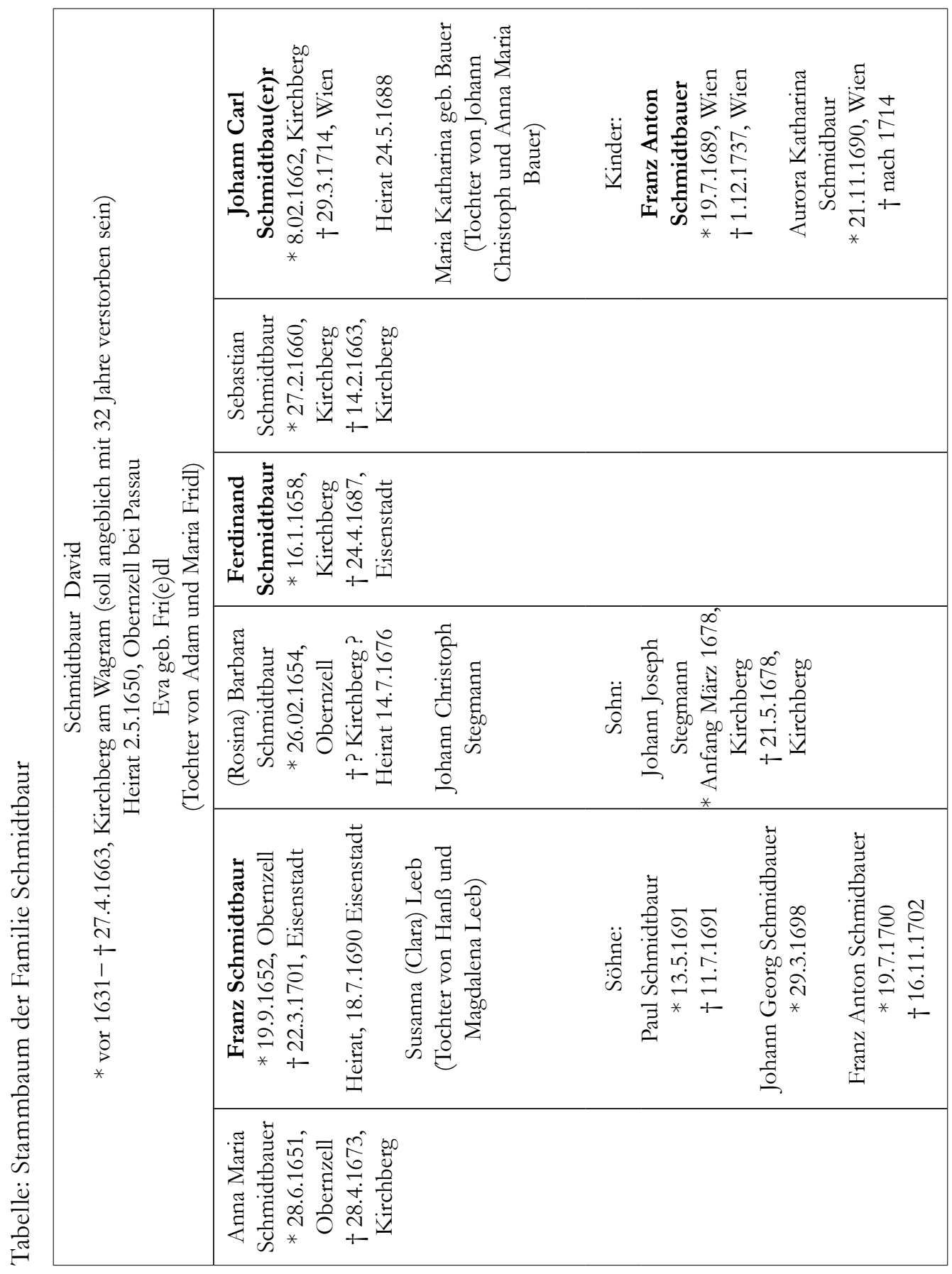

